\title{
Expert-GOSP - Expert System for Three-Phase Separator Diagnosis
}

\author{
Liviu IONIŢĂ, Irina IONIȚĂ \\ Petroleum-Gas University of Ploieşti, \\ 39, Bucureşti Blvd, Ploieşti, 100680, Romania, \\ lionita@gmail.com; tirinelle@yahoo.com
}

\begin{abstract}
Expert systems are known as artificial intelligence tools that store and implement human expert opinions, beliefs, methods and rules to achieve accurate system results. With the goal to assist the management of a gas-oil threephase separation plant, the authors created Expert-GOSP, a diagnosis tool based on expert system technology. The prototype is built in Exsys Corvid and the rules constituting the rules base of the expert system are provided by domain experts and additional documentation regarding the functioning of a real gas-oil separation plant from Romania.
\end{abstract}

Keywords: expert system, diagnosis, gas-oil industry, three-phase separator

\section{Introduction}

Expert systems are software packages that emulate the interaction between a person with a human expert in order to obtain a piece of advice or a recommendation regarding solutions to a problem from a well-defined domain. Specialized knowledge about how to solve problems (i.e. the methods) is often limited and difficult to discover, which represents a key element among competitive companies. Expert systems gather this knowledge and allow its dissemination to other individuals. The majority of approaches referring to knowledge distribution are based only on the person's capacity to understand and to transform knowledge into a usable form inside the organization. The role of expert systems is to directly transmit knowledge to the individuals, pieces of advice and recommendations more than information. As a result, difficult and complex decision problems are solved rapidly and efficiently without any additional training of human personnel involved in the process.

Application of expert systems is found in various domains such as: industry, medicine, telecommunication, banking, assurance etc. and aims at the diagnosis, prediction, analysis, situation or process planning. Oilfield production prediction, the assessment of fluid corrosion in oil and gas production wells, the selection of the candidate well for steaming up until the well is put on production, the detection of anomalies during industrial processes are just a few examples of expert system application.

An expert system is based on an inference engine, responsible with rationing (backward or forward chaining) and a knowledge base constituted from rules base and facts base. Knowledge representing the analyzed expert domain are implemented in two different ways: as data and as IF THEN ELSE rules.

In recent years, complex diagnosis problems have often been solved by means of intelligent diagnosis system [2]. Data mining techniques [10], multi-agent system [5][6], case-based reasoning systems [2], expert systems [1][11] are more and more applied for technical diagnosis in industry. The authors of this article focus their work in order to build an expert system as a diagnosis tool for a gas-oil separation plant (GOSP).

GOSP can be defined as an ensemble of industrial components used in the upstream oil industry. The role of GOSP is to separate the crude oil from sediments, solids and sand (below using a filter) and gases and then to allow the crude to be pumped on the pipeline system. A separator for petroleum production domain represents a large vessel designed to separate production fluids into their constituent components of oil, gas and water based on their different densities. When the fluid (crude oil) is moving slowly and the separation condition is achieved, the separation components are stratifying with gas on top, water on the bottom and oil in the middle (in a three-phase separator).

Expert-GOSP, the proposed system, collaborates with an intelligent agent named Diagnosis Agent (the supervisor agent from GOSP-MAS, a multi-agent system for diagnosis in oil industry [7]) in order to obtain diagnosis reports referring to the three-phase separator functioning. This paper describes the 
designing phase, the implementing phase and the testing phase of Expert-GOSP realized with Exsys Corvid [15][16]. The authors used more than ten evaluation scenarios for testing the prototype, two of them are given in the current article. A diagnosis report obtained after expert system execution contains the alarms, the identified faults and the adequate recommendations to solve the diagnosis problems. The paper is organized as follows: Section 2 represents an overview of expert systems, as decision tools, applied in oil industry. Section 3 gives information about description, implementation and testing of Expert-GOSP. Section 4 discusses about related work and Section 5 contains the conclusions of authors regarding the proposed diagnosis system based on expert systems technology.

\section{Expert Systems -as Decision Tools}

In industry, decisions are crucial and errors that initially are considered without major effects can disturb and cause disasters, involving equipment and people. Therefore, decision tools are very useful in such cases to help decision makers to do what is best referring to a situation/process. In literature [1][4][8][14] expert systems are often presented and considered as decision tools, easy to understand and with logical rationing, based on knowledge provided by experts in a certain domain. Motivated by the advantages of expert systems mentioned in the literature [2][3][11], the authors decided to build Expert-GOSP, a prototype system for diagnosis in oil industry by using knowledge-based systems technology. In the current section, there are discussed several examples of expert systems applied in gas-oil area as decision tools and a comparison with Expert-GOSP is made.

In [8] the authors describe an expert system for process supervision and diagnosis of an offshore oil product plant. The software used to implement the expert system was Gensym G2. In this paper the complete oil process is considered, including gas-oil separation process. In comparison with this diagnosis system, Expert-GOSP was built with ExsysCorvid and provides a diagnosis report with a list of faults, the causes of the faults and the recommendations only for a threephase separator.

Another example of knowledge-based system application in the oil industry is given in [12].
This article presents an approach to design a fuzzy logic controller to detect incipient abnormal production of wells in a reservoir. Simulation results presented in the paper [12] demonstrate how the designed controller detects well production fault, by using fuzzy IF THEN rules. Similarly, Expert-GOSP uses knowledge represented as heuristic rules in IF THEN ELSE form. The combination of all the heuristics allows the overall decision-making problem to be solved. The execution of the rules in Expert-GOSP was made through "Forward Chaining" which can be combined with Backward Chaining to run top level rules in a particular order.

In oil industry, human expertise is indispensable in the decision-making process of selecting the most adequate Enhanced Oil Recovery (EOR) method [9]. The goal of the project described in [9] is to develop an EOR knowledge-based expert system that allows oil organizations to input new data and modify the existing data for a certain well in order to select a proper conformance control method in Saskatchewan oil fields. The designed EOR expert system was formulated by representing the obtained knowledge using IF-AND-OR THEN-SELECT statements.

Similar to paper [12], the authors of [3] analyze oil well data chosen from distinct sources and propose a Fuzzy Petroleum Prediction (FPP) expert system. The main scope of fuzzy system proposed in [3] is to help petroleum engineers to detect areas adequate for the drilling process.

The above-mentioned examples indicate that most applications of expert systems in petroleum field fall into one of the following categories: interpreting and identifying, predicting, diagnosing, planning, monitoring and controlling.

In the next section of the current paper, the authors present Expert-GOSP in details (description of the system, implementation of knowledge base and testing phase).

\section{Expert-GOSP: Description, Implementation and Testing}

Exsys Corvid represents a software for generating expert systems and enables the decision-making logic and process of the domain expert to be converted into a structured form (IF THEN ELSE rules). The inference engine dynamically drives interactive sessions 
that provide advice and recommendation to end users [15][16].

Expert-GOSP was designed to collaborate with Diagnosis Agent, the supervisor agent of the multi-agent system GOSP-MAS [7] to obtain diagnosis reports referring to the function of a three-phase separator. Expert-GOSP contains a knowledge base, an inference engine and a GUI that enables the communication with Diagnosis Agent. The generated report after diagnosis is taken over by the Diagnosis Agent which collaborates with the Operator Agent, responsible with interpreting and executing the recommendations listed in the diagnosis report.

In Figure 1 there are represented the main modules of Expert-GOSP.

Expert-GOSP receives data referring to the operating parameters of the separator through the Diagnosis Agent. All the measurements of the system parameters (oil temperature inside the separator, oil temperature at the outlet of the heat exchanger, water level inside the separator, evacuated gas pressure etc.) received by the other agents of the multi-agent system GOSP-MAS are centralized in a database by the Diagnosis Agent. Expert-GOSP generates the diagnosis reports taking into account the experience of the engineers and operators of the gas-oil separation plant (representing the knowledge in gas-oil field) and the current conditions/states of the analyzed system (threephase separator).

The parameters considered in the designing phase of Expert-GOSP and with significance for the system diagnosis are:
1. oil temperature inside the separator (oil_temp_inside_separator);

2. oil temperature at the outlet of the heat exchanger 41HE002 (oil_temp_outlet_heat _exchanger_41HE002);

3. oil temperature at the outlet of the heat exchanger 41HE003 (oil_temp_outletheat_exchanger_41HE003);

4. pressure of the gases evacuated from the separator (gas_pressure_outlet_separator);

5. pressure of the water evacuated from the separator

(water_pressure_outlet_separator);

6. pressure of the oil evacuated from the separator (oil_pressure_outlet_separator);

7. water level inside the separator (water_level_separator);

8. oil level inside the separator (oil_level_separator).

The diagnosis report of Expert-GOSP contains information regarding the alarms caused by abnormal operating states of different plant sectors, the detected and identified faults and the solutions/recommendations proposed to remediate the functioning errors.

For expert system implementation there were used 14 attributes, including 8 attributes of Numeric type (the operating parameters of three-phase separator), 4 attributes of String type (alarm - the generated alarm, cause - the cause of alarm occurrence, solution - the solution/advice/recommendation and state - the

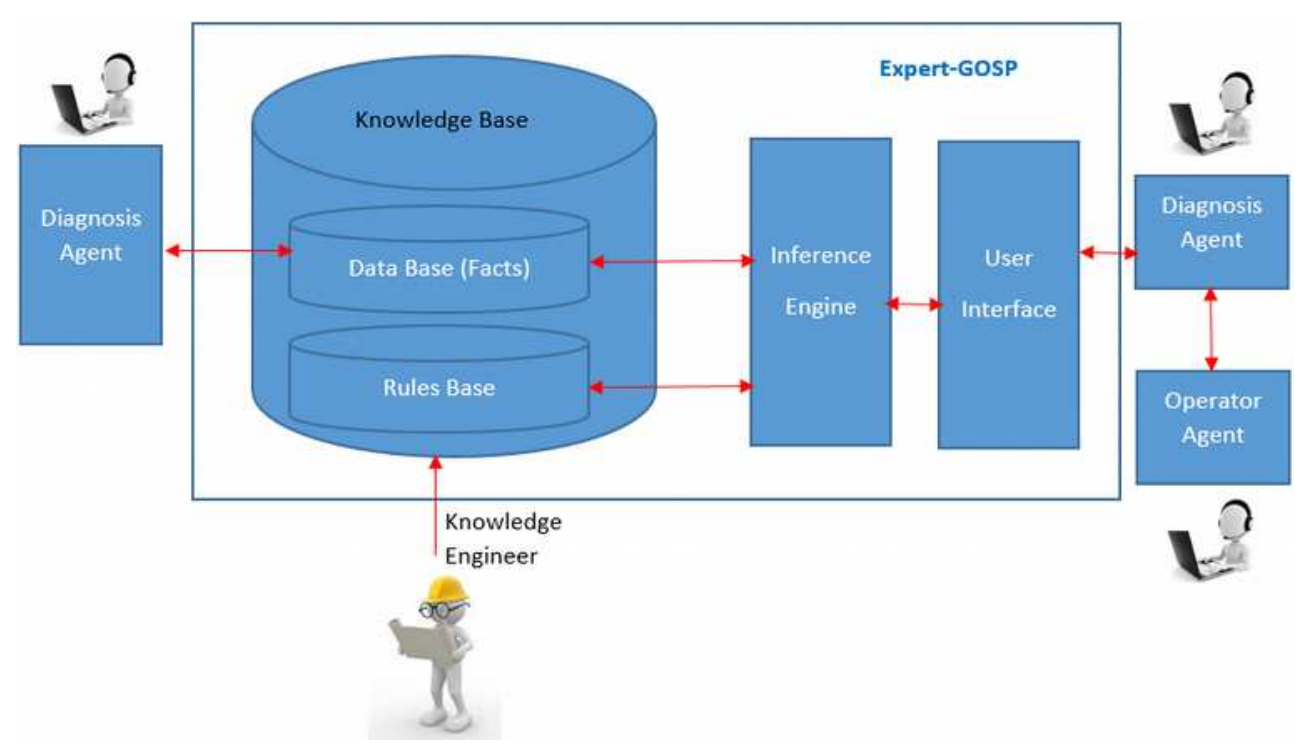

Figure 1. Expert-GOSP - expert system for a three-phase separator diagnosis 
operating state) and 2 attributes of Collection/Report type (report- the diagnosis report, state_report - the state of diagnosis report (elaborated/under development). Other 6 attributes were added for building rules acting at multiple levels (recommended_operation as Colelction/Report type and other $\overline{5}$ attributes as String type).

The rules stored in the rules base of expert system are presented in the well-known structure IF THEN ELSE, based on the technical documentation of gas-oil separation plant and the experience of the personal (engineers, operators etc.). Expert-GOSP uses the forward chaining to achieve the purpose, more exactly, to make the diagnosis of the three-phase separator.

An example of a set of rules is given in table 1 .

Table 1. Rules example

\begin{tabular}{|c|c|}
\hline R1 & $\begin{array}{l}\text { IF: } \\
\text { [oil_temp_inside_separator] }<=25 \\
\text { THEN: } \\
\text { [alarm] = " } \\
\text { separator LOW" } \\
\text { [cause] = " Cause: temperature control valve } \\
\text { fault TCV-41002 } \\
\text { or TCV-41003 or thermal insulation vessel } \\
\text { damage" } \\
\text { [solution] = " Solution: verify the operating } \\
\text { state of temperature control valve TCV- } \\
41002 / T C V-41003 \text { or verify thermal isolation } \\
\text { vessel" } \\
\text { SET [report.ADD] "TEMPEARTURE ALARM" } \\
\text { SET [report.ADD] [alarm.VALUE] } \\
\text { SET [report.ADD] [cause.VALUE] } \\
\text { SET [report.ADD] [solution.VALUE] }\end{array}$ \\
\hline R2 & 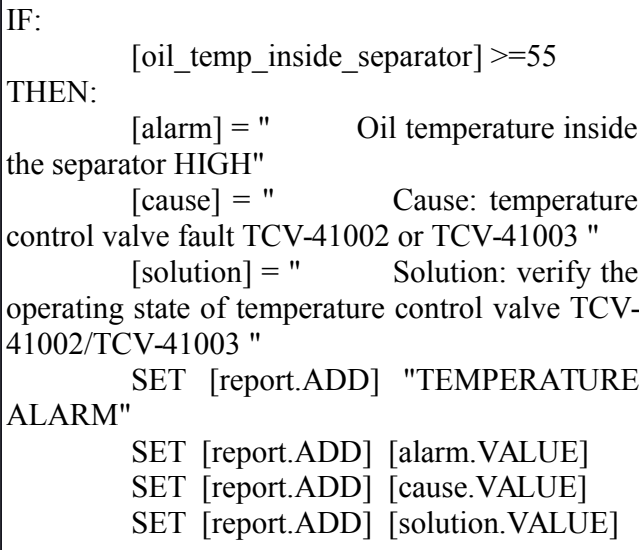 \\
\hline R3 & $\begin{array}{l}\text { IF: } \quad \text { [oil_temp_inside_separator] } \\
>25) \&([\text { oil_temp_inside_separator] }<55) \\
\text { THEN: } \quad \text { [state] }=" \quad \text { Oil temperature inside } \\
\text { the separator in normal range" } \\
\quad \text { SET } \quad \text { [report_state.ADD] }] \\
\text { [state.VALUE] }\end{array}$ \\
\hline R4 & IF: \\
\hline
\end{tabular}

\begin{tabular}{|c|c|}
\hline & 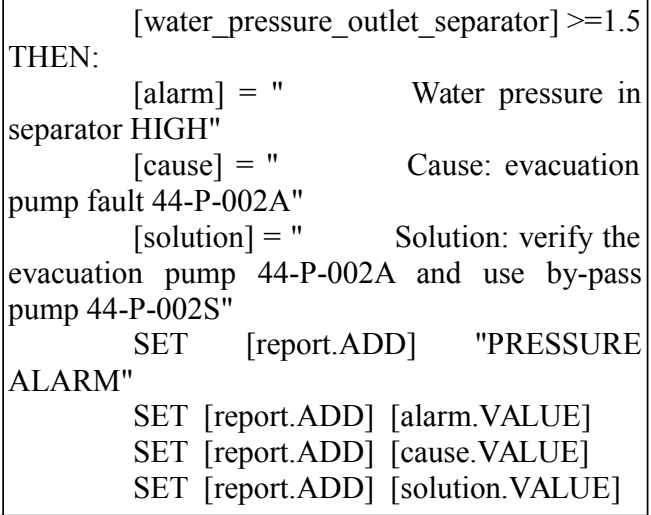 \\
\hline R5 & 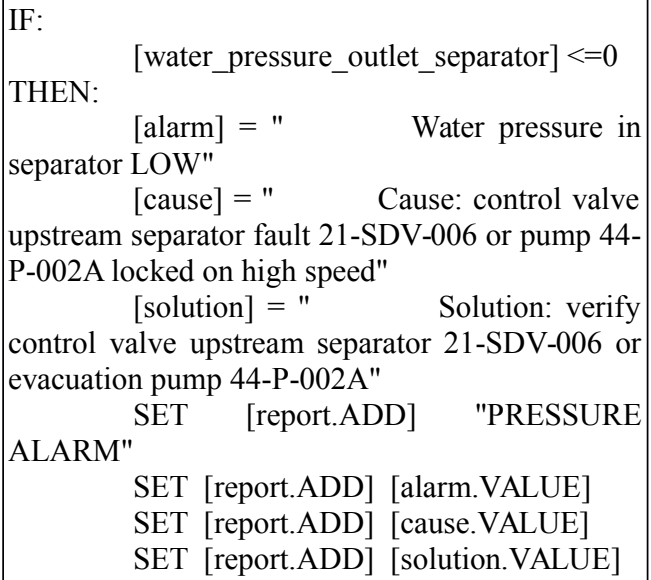 \\
\hline R6 & 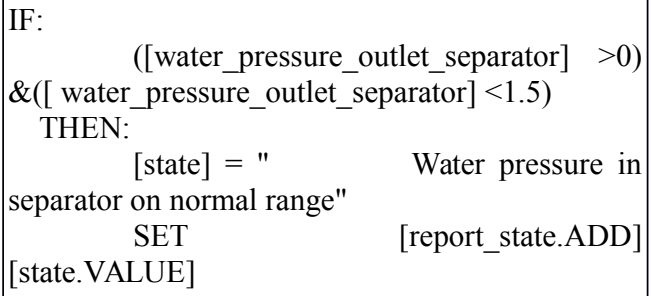 \\
\hline R7 & 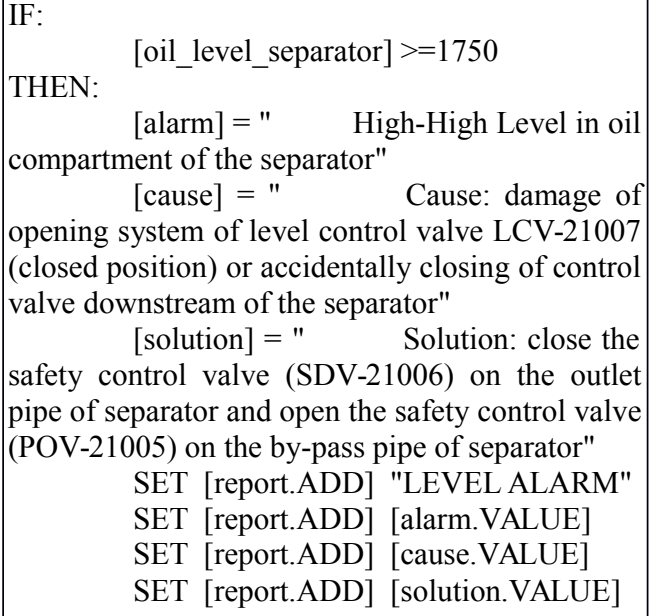 \\
\hline $\mathbf{R}$ & 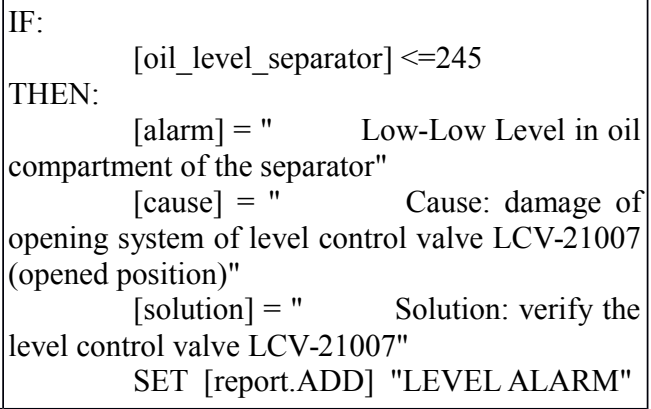 \\
\hline
\end{tabular}




\begin{tabular}{|c|c|}
\hline & $\begin{array}{l}\text { SET [report.ADD] [alarm.VALUE] } \\
\text { SET [report.ADD] [cause.VALUE] } \\
\text { SET [report.ADD] [solution.VALUE] }\end{array}$ \\
\hline R9 & 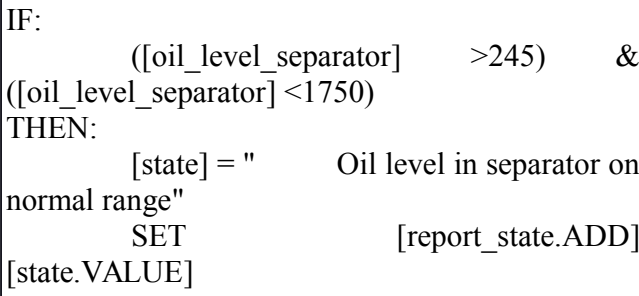 \\
\hline R10 & 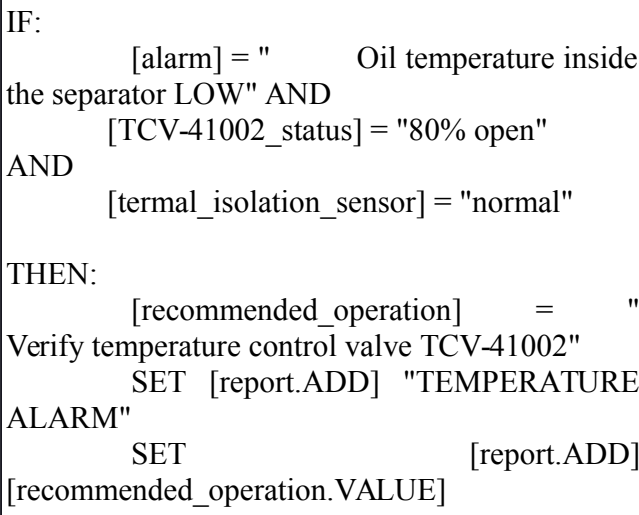 \\
\hline R11 & $\begin{array}{l}\text { IF: } \\
\text { [alarm] }=\text { "High-High Level in oil } \\
\text { compartment of the separator " AND } \\
\text { [LCV-21007_status] = "75\% open" } \\
\text { THEN: } \\
\text { [recommended_operation] = "Verify the } \\
\text { control valve downstream of the separator " } \\
\text { SET [report.ADD] " LEVEL ALARM" } \\
\text { SET [report.ADD] } \\
\text { [recommended_operation.VALUE] }\end{array}$ \\
\hline
\end{tabular}

The facts stored in the data base of expert system represent the measured values of operating parameters (the initial values) and the obtained values for various attributes during rationing process. An example of Expert-GOSP facts is: oil_level_separator $=1200 \mathrm{~mm}$, oil_pressure_outlet_separator $=5.12 \mathrm{bar}$, oil_temp_inside_separator $=23.45{ }^{\circ} \mathrm{C}$,

alarm $=$ "High-High Level in oil compartment of the separator", state=" Oil level in separator on normal range".

A possible scenario used to test the expert system is $S E 1$ : all the considered parameters have normal operating values (table 2).

Table 2. SE1 testing scenario

\begin{tabular}{|l|c|c|}
\hline Parameter & $\begin{array}{l}\text { Measured } \\
\text { value }\end{array}$ & $\begin{array}{l}\text { Measuring } \\
\text { unit }\end{array}$ \\
\hline oil_temp_inside_separator & 35.5 & ${ }^{0} \mathrm{C}$ \\
\hline $\begin{array}{l}\text { oil_temp_outlet_heat_exchanger } \\
\text { 411HE002 }\end{array}$ & 36.0 & ${ }^{0} \mathrm{C}$ \\
\hline $\begin{array}{l}\text { oil_temp_outlet_heat_exchanger } \\
\text { 411HE003 }\end{array}$ & 36.1 & ${ }^{0} \mathrm{C}$ \\
\hline gas_pressure_outlet_separator & 0.4 & bar \\
\hline water_pressure_outlet_separator & 1.2 & bar \\
\hline oil_pressure_outlet_separator & 8.15 & bar \\
\hline oil_level_separator & 1530 & $\mathrm{~mm}$ \\
\hline water_level_separator & 1200 & $\mathrm{~mm}$ \\
\hline
\end{tabular}

The diagnosis report generated after ExpertGOSP execution for SE1 scenario contains the values of the analyzed parameters and detailed information messages referring to the functioning state of the three-phase separator. As presented in Figure 2, all values are in the normal range and the messages are highlighted with green color indicating a normal state of functioning for the oil separation plant.

The SE2 testing scenario considers the following: the measurements of parameters

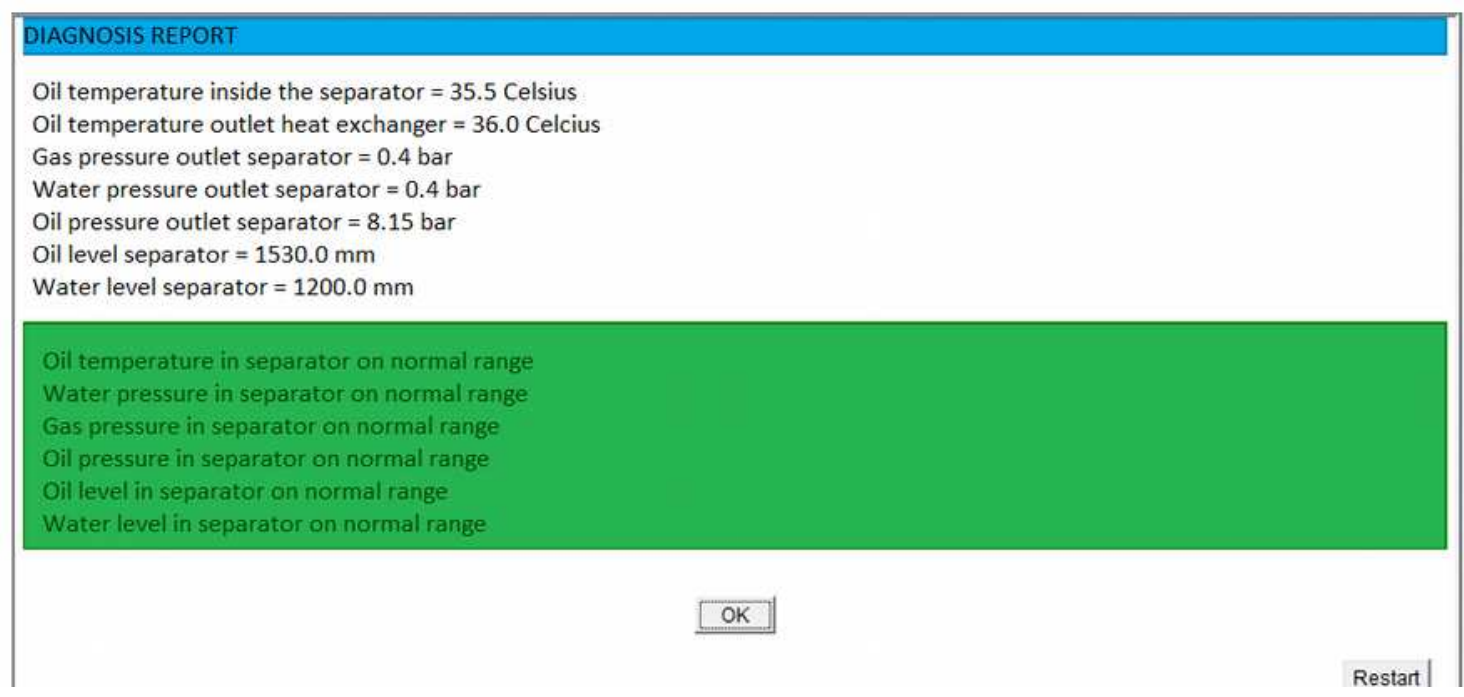

Figure 2. The diagnosis report for SE1 testing scenario 
oil_temp_outlet_heat_exchanger_41HE002, water_pressure_outlet_separator and oil_level_separator are out of normal range of operation (table 3 ).

Table 3. SE2 testing scenario

\begin{tabular}{|l|l|l|}
\hline Parameter & $\begin{array}{l}\text { Measured } \\
\text { value }\end{array}$ & $\begin{array}{l}\text { Measuring } \\
\text { unit }\end{array}$ \\
\hline oil_temp_inside_separator & 35.8 & $0 \mathrm{C}$ \\
\hline $\begin{array}{l}\text { oil_temp_outlet_heat_exchanger } \\
\text { 411HE002 }\end{array}$ & 25 & $0 \mathrm{C}$ \\
\hline $\begin{array}{l}\text { oil_temp_outlet_heat_exchanger } \\
\text { 411HE003 }\end{array}$ & 25.2 & $0 \mathrm{C}$ \\
\hline gas_pressure_outlet_separator & 0.67 & $\mathrm{Bar}$ \\
\hline water_pressure_outlet_separator & 1.55 & $\mathrm{Bar}$ \\
\hline oil_pressure_outlet_separator & 6.71 & $\mathrm{Bar}$ \\
\hline oil_level_separator & 1754 & $\mathrm{Mm}$ \\
\hline water_level_separator & 459 & $\mathrm{Mm}$ \\
\hline
\end{tabular}

The diagnosis report generated for the measured values of parameters mentioned in the SE1 testing scenario contains:

1. the values of the analyzed parameters;

2. the detailed information messages about normal values of the considered parameters;
3. the alarms, the causes and the solutions/ pieces of advice/recommendations offered for each case (temperature alarm, pressure alarm and level alarm).

An example of alarm is the following: the oil temperature at the outlet of the heat exchanger 41HE002 LOW, the water pressure inside the separator HIGH, Maxim Maximum level inside the oil compartment of separator. The identified causes for the alarms' occurrence are: temperature controller TCV-41002 breakdown, evacuation pump 44-P-002A breakdown, opening system for LCV-21007 (closed position) breakdown or accidental closing of the valve downstream of the separator. The solution given to remediate the functioning faults/errors of system may be described as: check the functioning state of the temperature controller TCV-41002, check the pump 44-P-002 operating condition, close the protection valve (SDV-21006) situated on the inlet pipe of the separator and open the protection valve (POV-21005) on the by-pass pipe of the separator.

The red sectors of the diagnosis report represent the alarms, the causes and the

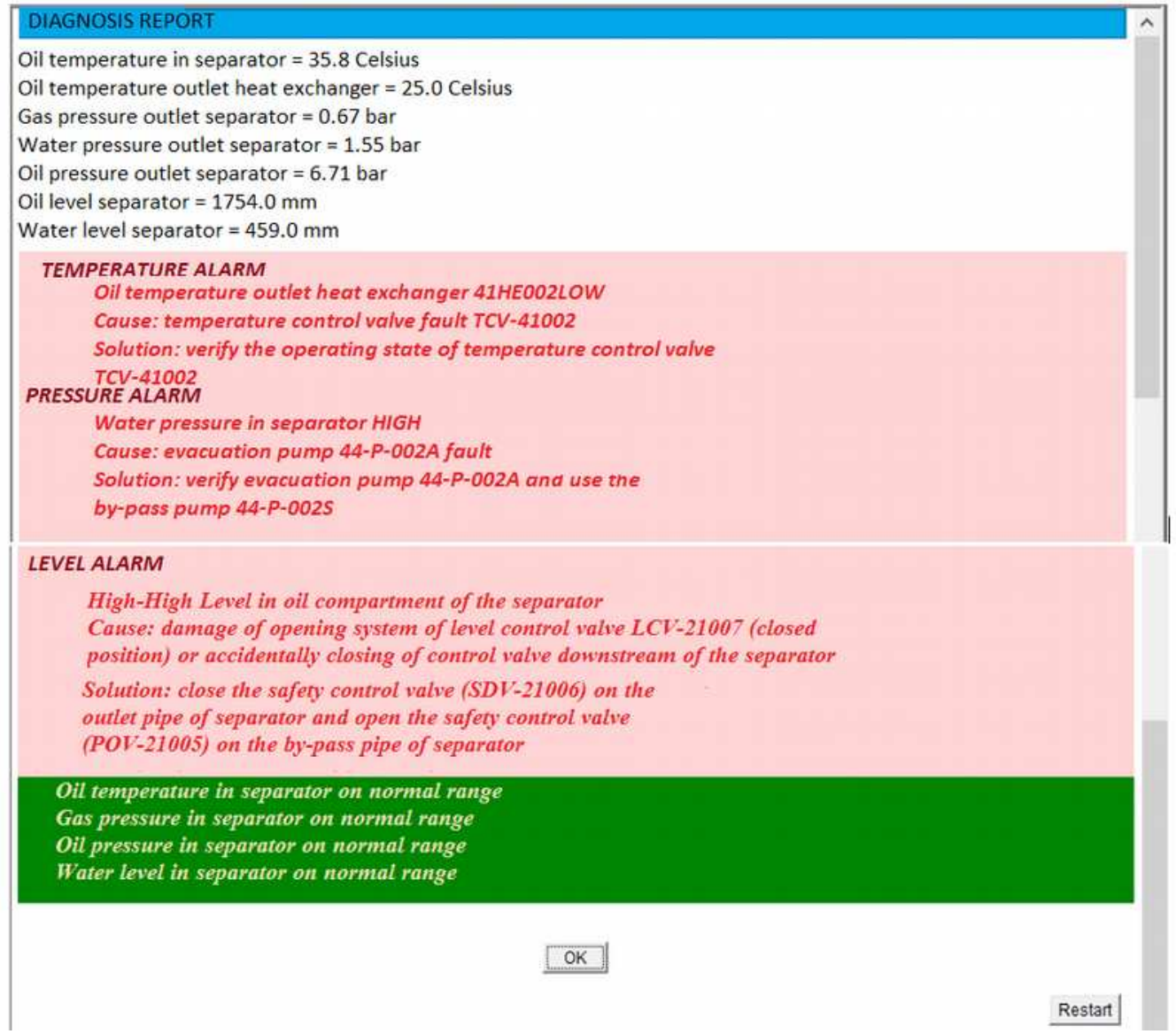

Figure 3. The diagnosis report for SE2 testing scenario 
adequate solutions for the SE2 testing scenario. The messages situated in the green sector describe the normal operating states (Figure 3).

The human operator analyses the diagnosis reports received from the Operator Agent (the agent which is responsible with the communication between human operator and GOSP-MAS) and executes operations necessary to remediate the anomalies occurred inside the gas-oil separation plant, according to the solutions/recommendations listed in the diagnosis report provided by Expert-GOSP.

Exsys Corvid owns the tracing facility to view the rationing method applied to solve the current problem (Run with Trace). The nodes of expert system are tested, and the rules' expressions are evaluated in order to establish their value (TRUE/FALSE).

In Exsys Corvid there is a type of variable named Confidence Variable referring to a variable that can be assigned as a confidence value to reflect a degree of certainty. Various formulas can be used to combine the values assigned for an overall confidence for the variable. The rules can include a "confidence factor" for a particular answer. This enables expert systems to provide multiple recommendations with differing degrees of confidence. While in some cases it is possible to give a specific recommendation/piece of advice with absolute precision, in other cases multiple recommendations are simultaneously possible and the system ranks them based on relative merit. The ability to handle confidence factors in Exsys Corvid provides a much more effective way to design expert systems that emulate the real world and give the type of solutions that human experts would.

\section{Discussions}

The authors' interest in knowledge-based systems (KBSs) applied in oil industry was found in previous work [4], were a prototype named KBS-Diag was developed in Visual Prolog with the main goal of monitoring and diagnosis of a GOSP. The authors used a group of parameters which are describing the status of the plant at a certain moment. KBS-Diag analyzed them and if a one or more parameters exceed the normal operating range, the inference engine starts the reasoning and try to identify the causes of these abnormal situation. As a result, on the user interface is displayed a message regarding to the alarms occurred and the solutions given.

Expert-GOSP extends the KBS-Diag and represents an improved version with important features:

1. a simply user interface but useful, due to the customized display areas for alarms and recommendations given (green area for normal situation, red area for abnormal situation), designed in Exsys Corvid;

2. a data base with facts collected from real situation of GOSP;

3. a rules base with IF THEN ELSE rules describing the multiple scenarios of system operating (extracted from process history), acting at multiple levels;

4. the ability of communication with an intelligent agent, to improve the quality of diagnosis;

5. the possibility of integration with other modules (for example with a Data Mining module for increase the accuracy of diagnosis);

6. the possibility to add confidence factors for optimizing the reasoning methods of expert system.

The simulations of Expert-GOSP were executed on concrete facts provided by operating reports during a week. The current monitoring and diagnosis system implemented on the concerned GOSP on the oil field, displays only the current alarms and a history of alarms, with certain features: severity, time (data and hour) of alarm occurrence, time (date and hour) of exiting alarm, alarm message, alarm state (normal, in alarm). Expert-GOSP supplementary offers solutions to the human operator to solve the failures, if it is possible.

\section{Conclusions}

Expert-GOSP is an expert system developed for assisting the maintenance and operations departments with the diagnosis and correction of failures within the gas-oil separation plant. The use of this expert system will help to reduce the down-time and repetitive start-ups by diagnosing the cause of the shut-down before restarting the plant or other type of failures. The overall reliability and availability of the plant should improve the separation process of crude oil and will increase the 
operating and maintenance costs. The data used to develop the database of Expert-GOSP, the rules base and the testing data were provided by concrete operating reports of a gas-oil separation plant from Romania. Multiple evaluation scenarios were used to analyze the behavior of the designed expert system, based on functioning of GOSP during a week. Future work will focus on adding confidence factors to the rules of expert system and to combine data mining techniques with expert system technology to increase the accuracy of results.

\section{REFERENCES}

1. ANGELI, C., Diagnostic Expert Systems: From Expert's Knowledge to Real-time Systems. Book: Advanced knowledge based systems: Model, Application \&Research, Sajjia \&Akerkar (eds), 2010, pp. 50-73.

2. BALAKRISHNAN, K., V. HONAVAR, Intelligent Diagnosis Systems, J. of Intel. Sys., vol. 8(3-4), 1998, pp. 239-290.

3. GHALLAB, S. A., N. BADR, A. B. SALEM, M. F. TOLBA, A Fuzzy Expert System For Petroleum Prediction, WSEAS, Croatia, 2, 2013, pp.77-82.

4. IONIȚĂ, I., L. IONIŢĂ, A KnowledgeBased System for Diagnosis in Oil Industry, The 19th Intl. Conf. The Knowledge-Based Organization KBO 2013, Conference Proceedings 3 Applied Technical Sciences and Advanced Military Technologies, 2013, pp. 277-280.

5. IONIŢĂ, L., I. IONIȚĂ, A Methodology for Agent-Oriented Systems Development Applied in Oil Industry, Studies in Informatics and Control, Vol. 23(3), 2014, pp. 239-248.

6. IONIŢĂ, L., Multi-agent System Used for Technical Diagnosis in Gas-Oil Separation Plant, The 20th International Conference The Knowledge-Based Organization, Applied Technical Sciences and Advanced Military Technologies, Conference proceedings 3, „NicolaeBălcescu” Land Forces Academy Publishing House, Sibiu, 2014, pp. 42-47.

7. IONIŢĂ, L., Sistem multi-agent pentru diagnoză tehnică aplicat în industria de petrol, teză de doctorat, Universitatea Politehnica din București, Școala doctorală Automatică și Calculatoare, 2014.
8. KASZKUREWICZ, E., BHAYA, A., EBECKEN, N.F.F., A Fault Detection and Diagnosis Module for Oil Production Plants in offshore Platforms, Expert Systems with Applications, Vol.12, No.2, 1994, pp.189-194.

9. KOOROSH, A., Final Report for the Petroleum Technology Research Center, Enhanced Oil Recovery (EOR) Knowledge-Based Expert System for Conformance Control in Saskatchewan Reservoirs, 2005, http://steps.ptrc.ca/concrete/files/5714/1029 /3914/Enhanced_Oil_Recovery_EOR_Kno wledge-based_Expert_Sytems_for Conformance...___Final_Report.pdf

10. NAMIKKA, E., G. J. GIBBON, Identification of Data Mining Techniques for Industrial Process Analysis and Control, School of Electrical and Information Engineering, University of the Witwatersrand, Johannesburg, 2002

11. NAN, C., F. KHAN, M. T. IQBAL, Realtime Fault Diagnosis using Knowledgebased Expert System, Process Safety and Environmental Protection, vol. 86(1), 2008, pp. 55-71.

12. ODEDELE, T. O., H. D. IBRAHIM, Oil Well Performance Diagnosis System Using Fuzzy Logic Inference Models, Proceedings of the World Congress on Engineering 2014 Vol I, WCE 2014, July 2 - 4, 2014, London, U.K, ISBN: 978-98819252-7-5, ISSN: 2078-0958 (Print); ISSN: 2078-0966 (Online).

13. PIATETSKY-SHAPIRO, G., R. J. BRACHMAN, T. KHABAZA, W. KLOESGEN, E. SIMOUDIS, An Overview of Issues in Developing Industrial Data Mining and Knowledge Discovery Applications, In KDD, 96, 1996, pp.88-95

14. STANESCU, I. A., V. STEFAN, G. NEAGU, Renewable Energy Decision Support Systems: The Challenge of Data Integration, Studies in Informatics and Control, Volume 24, Issue 2, ISSN 12201766, 2015, pp. 191-200.

15. http://www.exsys.com/CorvidCore/Corvid CoreAdvancedTutorial.pdf

16. http://www.exsys.com/PDF/CorvidManual. pdf 